\title{
Comparison of immunoperoxidase staining with indirect immunofluorescence, ELISA, and Western blotting assays for detecting anti-HTLV-I antibodies in systemic lupus erythematosus
}

\author{
K YAMAGUCHI, ESTELA MATUTES, T KIYOKAWA, * YOKO NISHIMURA, \\ T ISHII, ${ }^{*}$ K TAKATSUKI, ${ }^{*}$ D CATOVSKY \\ From the Medical Research Council Leukaemia Unit, Royal Postgraduate Medical School, London, and the \\ * Blood Transfusion Service and Department of Internal Medicine, Kumamoto University Medical School, \\ Kumamoto, Japan
}

\begin{abstract}
Serum antibodies against human $T$ cell leukaemia virus type I (HTLV-I) were investigated in 12 patients by four methods: indirect immunoperoxidase staining, indirect immunofluorescence, enzyme linked immunosorbent assay (ELISA), and strip radioimmunoassay based on the Western blotting assay. Seven patients had systemic lupus erythematosus (SLE) and five various autoimmune diseases with one or more circulating autoantibodies. Serum samples from three patients were found to be HTLV-I-positive by the ELISA assay and sera from five patients showed a non-specific reaction by indirect immunofluorescence. These sera were negative when tested by indirect immunoperoxidase staining and Western blotting assay. All four methods gave positive results when tested with samples from 19 HTLV-I carriers and 16 patients with adult T cell leukaemia. Indirect immunoperoxidase staining and Western blotting assay are probably useful and more specific assays for the detection of anti-HTLV-I antibodies in samples from patients with autoimmune diseases.
\end{abstract}

Several methods to detect antibodies against HTLVI-namely, indirect immunofluorescence using fixed MT-I cells,' membrane immunofluorescence, solid phase immunocompetition assay, ${ }^{23}$ enzyme linked immunosorbent assay (ELISA), ${ }^{4}$ gelatin particle agglutination, ${ }^{5}$ and strip radioimmunoassay, based on the Western blotting assay, ${ }^{6}$ have been reported. There are still difficulties, however, in detecting specific antiHTLV-I antibodies in patients with autoimmune disease with circulating autoantibodies. Indeed, with indirect immunofluorescence and ELISA assays it is not always easy to exclude a non-specific reaction. In this study we investigated the presence of antibodies to HTLV-I in the sera from patients with systemic lupus erythematosus and other autoimmune diseases by several of the above methods and a new immunoperoxidase technique.

Accepted for publication 4 August 1987

\section{Material and methods}

PATIENTS WITH AUTOIMMUNE DISEASE

Sera from seven patients with systemic lupus erythematosus and five patients with progressive systemic sclerosis $(n=1)$, idiopathic thrombocytopenic purpura $(n=1)$, Sjögren's syndrome $(n=1)$, polymyositis, $(n=1)$, and rheumatoid arthritis $(n=$ 1), treated in Kumamoto (an area where the incidence of HTLV-I infection is high) were studied. All were women aged between 28 and 67 years who had one or more circulating autoantibodies (anti-DNA, antimitochondria, thyroid autoantibodies etc). As positive controls, sera from 16 patients with adult $T$ cell leukaemia (ATL) and 19 HTLV-I carriers were tested by indirect immunofluorescence, and sera from 26 healthy subjects were used as negative controls.

SCREENING OF SERA FOR ANTI-HTLV-I ANTIBODIES

Serum samples were surveyed for anti-HTLV-I antibodies by indirect immunofluorescence, ELISA, 
Western blotting assay and indirect immunoperoxidase staining. The procedure for indirect immunofluorescence was as follows. ' MT-1 cells fixed in acetone $^{7}$ were reacted with diluted sera and then fluorescein isothiocyanate conjugated goat antihuman IgG was added and incubated at $37^{\circ} \mathrm{C}$ for 30 minutes. The MT-1 cell line was derived from peripheral blood leukaemic cells from a patient with ATL. As described previously, ${ }^{1}$ cells bearing HTLV-I associated antigens (ATLA) in MT-1 cells are few (1-2\%), and almost all MT-1 cells do not express ATLA. Anti-HTLV-I antibodies, positive, and negative reference sera were included in each test as parallel controls. Sera showing bright fluorescence at a $1 / 10$ dilution were regarded as positive. The fluorescence was somewhat granular, often appearing as large aggregates in the cytoplasm but not in the nucleus of the cells. On the other hand, reactions showing diffuse stain in both cytoplasm and nucleus were regarded as non-specific.

The procedure for ELISA (Eisai Kit, Tokyo, Japan) was as follows. ${ }^{4}$ Coated with antigen solution, extracted MT-2 cells ${ }^{8}$ were reacted with diluted sera in plastic cups and then with alkaline phosphate labelled mouse antihuman IgG monoclonal antibody at $37^{\circ} \mathrm{C}$ for 60 minutes. The MT- 2 cell line was established from cord blood lymphocytes cocultivated with leukaemic cells from a patient with ATL. Most MT-2 cells release a large number of virus particles. After adding a $p$ nitrophenyl phosphate solution at $37^{\circ} \mathrm{C}$ for 60 minutes the reaction was stopped by the addition of $4 \mathrm{~N} \mathrm{NaOH}$. The absorbence at $405 \mathrm{~nm}$ was measured using a spectrophotometer. The cut off value of ELISA was the mean value for serum samples obtained from 104 healthy subjects determined to be antibody negative by the indirect immunofluorescence assay plus three times the standard deviation. Absorbence readings of more than 0.400 were considered to be positive.

Western blotting assay was performed as follows. Cell lysates were obtained by incubating 10 million MT-2 cells in $1 \mathrm{ml}$ of lysing buffer $(10 \mathrm{mM}$ Trishydrochloric acid, $\mathrm{pH} 7 \cdot 2$, containing $0.9 \%$ sodium chloride, $0.5 \%$ NP-40 and $2 \mathrm{mM}$ phenylmethylsulfonyl fluoride) for 20 minutes on ice. After removing cell debris at $150000 \mathrm{rpm}$ for 10 minutes recovered proteins were diluted $1 / 1$ with Laemmli sample buffer and electrophoresed on $12 \%$ polyacrylamide in the presence of sodium dodecyl sulphate (SDS). The separated protein was electroblotted on nitrocellulose sheets by the Western blotting technique. The virus strip radioimmunoassay was done by the methods described previously, ${ }^{9}$ using non-fat dried mild instead of bovine serum albumin to prevent non-specific binding of proteins to the nitrocellulose.

Indirect immunoperoxidase was performed as follows. ${ }^{10} \mathrm{C} 91 / \mathrm{PL}$ cells fixed in acetone were reacted with diluted sera for 30 minutes at $37^{\circ} \mathrm{C}$ in a moist chamber and then with peroxidase conjugated rabbit antihuman immunoglobulin (Dako, Denmark) at $37^{\circ} \mathrm{C}$ for 30 minutes. The C91/PL cell line was established from cord blood lymphocytes cocultivated with HTLV-I positive neoplastic T cells." The C91/PL cell line is also a high producer of HTLV-I viral particles. The cytochemical reaction was developed for five minutes with $30 \mathrm{mg}$ of diaminobenzidine tetrahydrochloride (DAB, Sigma) in $50 \mathrm{ml}$ of PBS and $20 \mu$ lof hydrogen peroxide ( $30 \mathrm{vol})$, and then washed in PBS and distilled water and counterstained with Harris's haematoxylin. Sera showing peroxidase activity in a multiple granular pattern were considered to be positive.

Table HTLV-I antibodies in autoantibody positive sera

\begin{tabular}{|c|c|c|c|c|c|c|}
\hline Case No & Age/Sex & Diagnosis & $E L I S A$ & $\begin{array}{l}\text { Indirect } \\
\text { immuno- } \\
\text { fluores- } \\
\text { cence }\end{array}$ & $\begin{array}{l}\text { Western } \\
\text { blotting } \\
\text { assay }\end{array}$ & $\begin{array}{l}\text { Indirect } \\
\text { immuno- } \\
\text { peroxidase } \\
\text { staining }\end{array}$ \\
\hline 1 & $35 / F$ & Systemic lupus erythematous & - & - & - & - \\
\hline 2 & $28 / F$ & Systemic lupus erythematous & - & - & - & - \\
\hline 3 & $41 / \mathrm{F}$ & Systemic lupus erythematous & - & NS & - & - \\
\hline 4 & $36 / F$ & Systemic lupus erythematous & - & - & - & - \\
\hline 5 & $39 / F$ & Systemic lupus erythematous & - & - & - & - \\
\hline 6 & $45 / F$ & Systemic lupus erythematous & - & NS & - & - \\
\hline 7 & $38 / F$ & Systemic lupus erythematous & 0.676 & NS & - & - \\
\hline 8 & $52 / \mathrm{F}$ & Progressive systemic sclerosis & - & NS & - & - \\
\hline 9 & $37 / F$ & Idiopathic thrombocytopenic purpura & - & - & - & - \\
\hline 10 & $62 / \mathrm{F}$ & Sjögren's syndrome & 0.566 & - & - & - \\
\hline 11 & $46 / \mathrm{F}$ & Polymyositis & 0.623 & NS & - & - \\
\hline 12 & $67 / \mathrm{F}$ & Rheumatoid arthritis & - & - & - & - \\
\hline \multirow{3}{*}{\multicolumn{2}{|c|}{$\begin{array}{l}\text { ATL } \\
\text { HTLV-I carriers } \\
\text { Healthy subjects }\end{array}$}} & $(n=16)$ & $0 \cdot 870$-overscale* & + & + & + \\
\hline & & $(n=19)$ & 1.043-overscale & + & + & + \\
\hline & & $(n=26)$ & $<0.400$ & - & - & - \\
\hline
\end{tabular}

${ }^{*}$ range; NS, non-specific staining. 

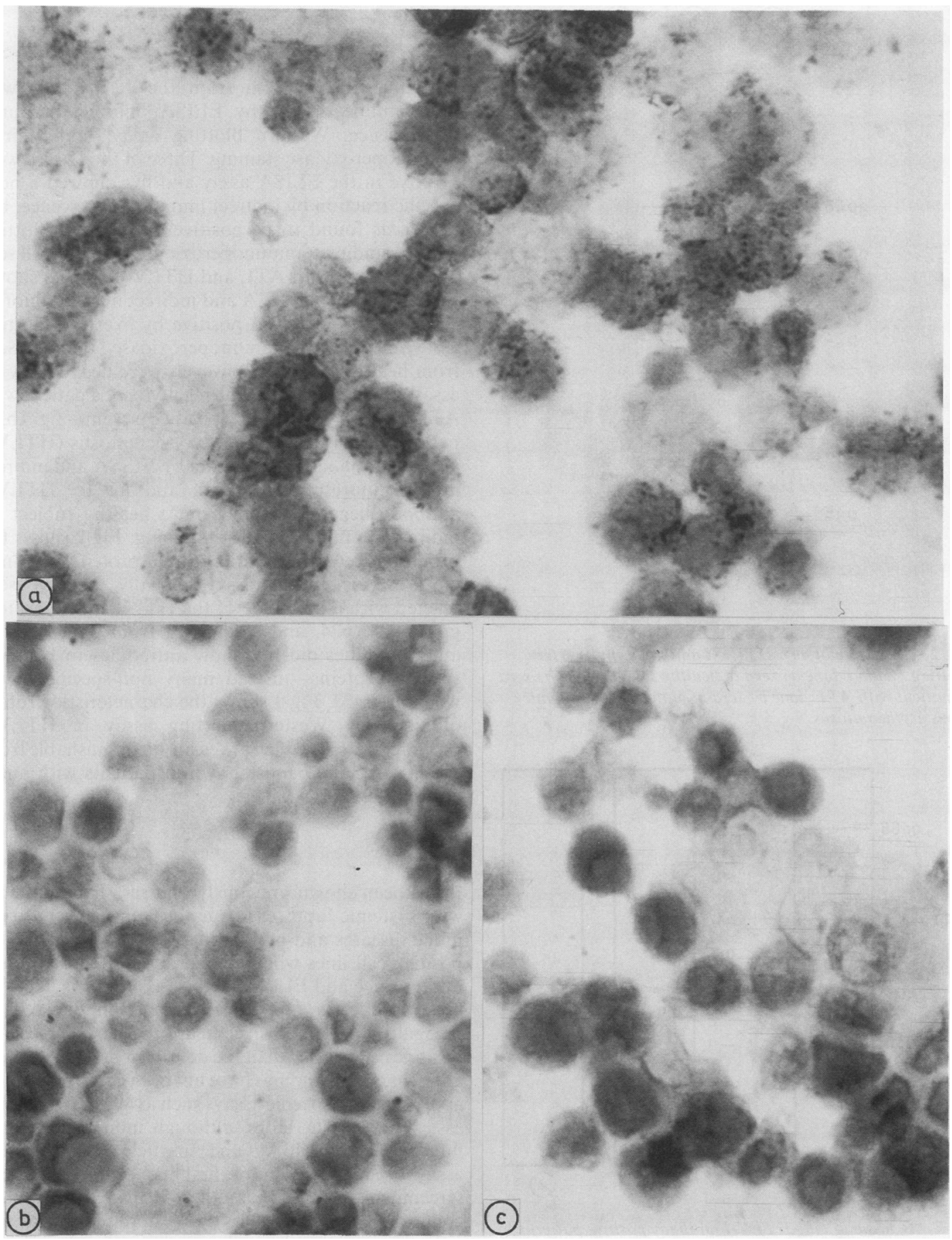

Fig 1 Photomicrographs of detection of anti-HTLV-I antibodies by indirect immunoperoxidase staining: (a) positive (patient with ATL); (b) negative (healthy subject); (c) negative (patient with systemic lupus erythematosus). 


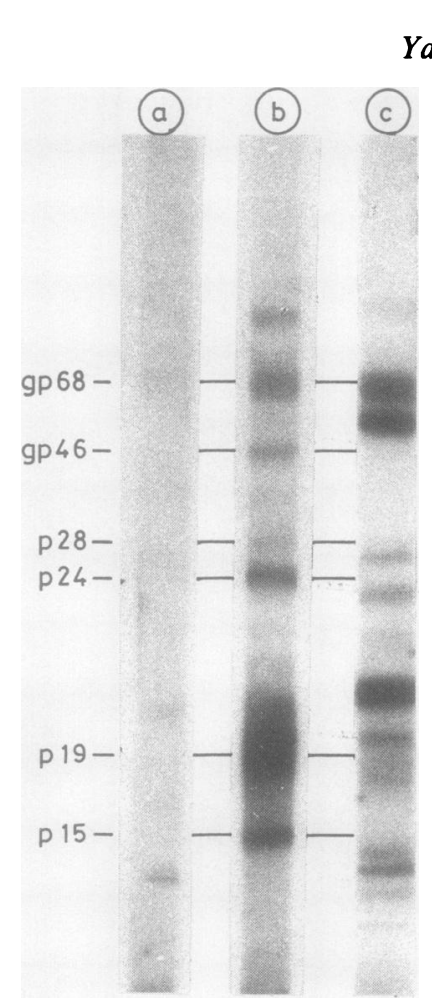

Fig 2 Detection of anti-HTLV-I antibodies by Western blotting method: lane a) sera of healthy subject; lane b) sera of patient with ATL; lane c) sera of patient with systemic lupus erythematosus.

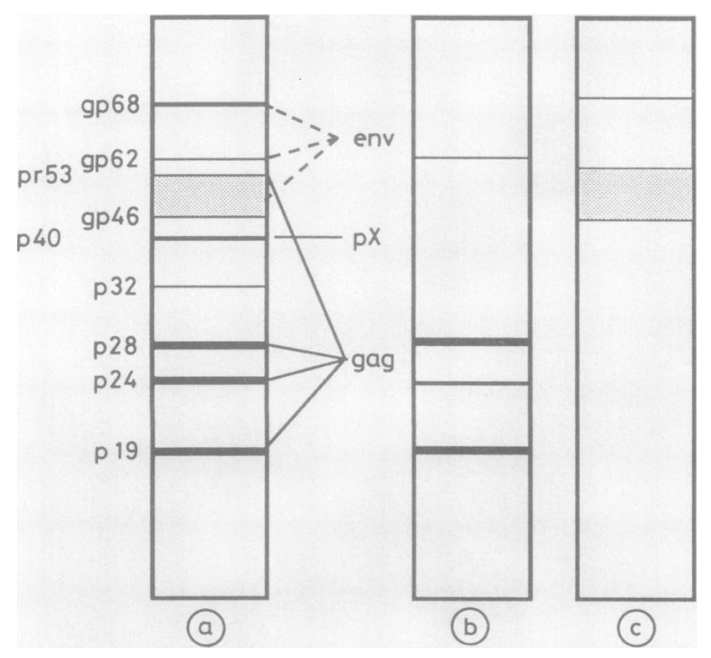

Fig 3 Scheme of anti-HTLV-I antibody positive patterns by Western blotting method: (a) $90 \%$ of positive sera show both anti-gag and env gene products of HTLV-I; (b) $5 \%$ of positive sera show only anti-gag gene products; (c) $<5 \%$ of positive sera show only anti-env gene products.
Results

The table shows the incidence of anti-HTLV-I 을 antibodies in the sera from the 12 patients with $\overrightarrow{\vec{\sigma}}$ autoimmune disease by ELISA, indirect immunofluorescence, Western blotting assay, and indirect immunoperoxidase staining. Three of the 12 sera were $\frac{\bar{\sigma}}{\bar{\omega}}$ positive in the ELISA assay and five showed a non- $\vec{\nabla}$ specific reaction by indirect immunofluorescence, but $\propto$ none was found to be positive by Western blotting के assay or indirect immunoperoxidase staining. All sera $\vec{\circ}$ from patients with ATL and HTLV-I carriers shown to be positive by ELISA and indirect immunofluores- $\vec{\omega}$ cence assays were also positive by Western blotting $\frac{\Omega}{2}$ assay and indirect immunoperoxidase staining. Sera ? from healthy subjects, however, were negative by all $\oplus$ assays. Fig la illustrates the reactivity of a patient with $\overrightarrow{0}$ ATL (HTLV-I antibody positive serum); fig $1 \mathrm{~b}$, a Vु patient with systemic lupus erythematosus (HTLV-I 윽 antibody non-specific reaction by ELISA and indirect immunofluorescence assays); and fig 1c, HTLV-I cे antibody negative serum from a healthy subject by indirect immunoperoxidase-staining. Fig 2 shows the profiles of recognised virus related proteins obtained by Western blotting assay. Usually, positive sera $\ddot{\bullet}$ reacted with all or some of the HTLV-I glycoprotein gp46, p28, p24, and p19 ${ }^{12}$; sera from patients with autoantibodies did not show antibodies to HTLV-I specific proteins-instead many non-specific bands were observed. Fig 3 shows the characteristic profiles obtained by Western blotting assay in HTLV-I $\stackrel{\mathbb{\perp}}{\mathbb{D}}$ positive patients, which are easily distinguishable from $\overrightarrow{\vec{P}}$ the non-specific bands shown in patients with autoantibodies.

\section{Discussion}

It has been shown previously that sera from patients with systemic lupus erythematosus or other autoimmune diseases and malaria may react with HTLV-Ipositive cell lines when studied by indirect immunofluorescence and ELISA methods. ${ }^{1314}$ This is likely to be caused by a false positive reaction due to the $D$ recognition of unknown cellular proteins on HTLV-Ipositive cells rather than the detection of virus specific $N$ antigens, as the findings have not been confirmed when applying more specific assays such as Western blotting assay (fig 2). Therefore, although indirect immunofluorescence, ELISA, and particle agglutination assays are relatively simple first line techniques for the screening of blood donors, there is always the need to confirm the positive results by Western blotting assay.

In this study we have shown that a simple indirect immunoperoxidase staining method, which is commonly used to detect cytoplasmic antigens and the nuclear enzyme terminal deoxynucleotidyl transferase 
(TdT), may be useful and more specific than indirect immunofluorescence and ELISA to detect antibodies to HTLV-I. Thus sera from all six patients which showed a non-specific reaction for HTLV-I antibodies when assessed by indirect immunofluorescence or ELISA, or both, were shown to be unreactive with the indirect immunoperoxidase staining method. The indirect immunoperoxidase staining method always showed clearly granular positive patterns in sera from patients with ATL and in HTLV-I carriers. These results were further confirmed by the Western blotting assay.

A similar indirect immunoperoxidase staining method has previously been reported to be useful in detecting the presence of antibody to HTLV-III, ${ }^{15}$ and it has been shown that results obtained by indirect immunoperoxidase staining are comparable with those of the indirect immunofluorescence method. The indirect immunoperoxidase staining method, however, has not been applied systematically to investigate sera from patients with autoantibodies, which may show a non-specific pattern of reactivity by indirect immunofluorescence and the ELISA methods. In this study we have shown that the indirect immunoperoxidase staining method may be more specific than the indirect immunofluorescence and ELISA methods as, unlike indirect immunofluorescence and ELISA, a non-specific reaction has not been detected by indirect immunoperoxidase staining. In relation to the ELISA assay, we performed the standard ELISA test by an antiglobulin technique; it is possible, however, that a competitive ELISA technique might avoid some of the difficulties (non-specific staining) derived from the standard ELISA test and therefore might be as specific as the indirect immunoperoxidase staining method. We have also shown that indirect immunoperoxidase staining is equally sensitive for testing samples of HTLV-Ipositive subjects (healthy carriers and ATL patients). In fact, the indirect immunoperoxidase staining method described here seems to be reliable, relatively simple, and reproducible, and can be used as a first line screening method for HTLV-I antibody.

Although a role for viruses in the aetiology of systemic lupus erythematosus has been regarded as feasible, ${ }^{17}$ the role of HTLV-I has not been confirmed. ${ }^{18}$ Our data further suggest that HTLV-I does not play a part in the pathogenesis of systemic lupus erythematosus.

KY was supported by the Yamagiwa-Yoshida Memorial International Study Grant awarded by the International Union Against Cancer. EM was supported by the Leukaemia Research Fund of Great Britain.

\section{References}

1 Hinuma Y, Nagata K, Hanaoka M, et al. Adult T-cell leukaemia: antigen in an ATL cell line and detection of antibodies to the antigen in human sera. Proc Natl Acad Sci USA 1981;78: 6476-80.

2 Posner LE, Robert-Guroff M, Kalyanaraman VS, et al. Natural antibodies to the human T-cell lymphoma virus in patients with cutaneous T-cell lymphomas. J Exp Med 1981;154:333-46.

3 Palker TJ, Scearce RM, Miller SE, et al. Monoclonal antibodies against human T-cell leukaemia-lymphoma virus (HTLV) p24 internal core protein. J Exp Med 1984;159:1117-31.

4 Taguchi H, Sagawa T, Fugishita M, Morimoto T, Niiya K, Miyoshi I. Enzyme-linked immunosorbent assay of antibodies to adult T-cell leukaemia-associated antigens. Gann 1983; 74:185-7.

5 Ikeda M, Fujino R, Matsui T, Yoshida T, Komoda H, Imai J. A new agglutination test for serum antibodies to adult $\mathrm{T}$-cell leukaemia virus. Gann 1984;75:845-8.

6 Chosa T, Hattori T, Matsuoka M, Yamaguchi K, Yamamoto S, Takatsuki K. Analysis of anti-HTLV-I antibodies by strip radioimmunoassay-comparison with indirect immunofluorescence assay, enzyme-linked immunosorbent assay and membrane immunofluorescence assay. Leukemia Res 1986;10: 605-10.

7 Miyoshi I, Kubonishi I, Sumida M, et al. A novel T-cell line derived from adult T-cell leukaemia. Gann 1980;71:155-6.

8 Miyoshi I, Kubonishi I, Yoshimoto S, et al. Type C virus particles in a cord T-cell line derived by cocultivating normal human cord leukocytes and human leukaemic T-cells. Nature 1981;294: $770-1$.

9 Towbin H, Staehelin T, Gordon J. Electrophoretic transfer of proteins from polyacrylamide gels to nitrocellulose sheets: procedure and some applications. Proc Natl Acad Sci USA 1979;76:4350-4.

10 Matutes E. Cell markers in diagnostic haematology. In: Polak JM, Van Noorden S, eds. Immunocytochemistry. 2nd ed. Bristol: John Wright \& Sons, 1986:599-617.

11 Popovic M, Lange-Wantzin G, Sarin PS, Mann D, Gallo RC. Transformation of human umbilical cord blood $\mathrm{T}$ cells by human T-cell leukaemia/lymphoma virus. Proc Natl Acad Sci USA 1983;80:5402-6.

12 Hottori S, Kiyokawa T, Imagawa K, et al. Identification of gag and env products of human T-cell leukaemia virus. Virology 1984;136:338-47.

13 Taguchi H, Kitagawa T, Fujishita M, Niiya K, Miyoshi I. Analysis of anti-ATLA antibody by enzyme immunoassay kit. Rinsho Kensa 1985;29:91-4.

14 Biggar RJ, Gigase PL, Melbye M, et al. ELISA HTLV retrovirus antibody reactivity associated with malaria and immune complexes in healthy Africans. Lancet 1985; ii:520-3.

15 Karpas A, Gillson W, Bevan PC, Oates JK. Lytic infection by British AIDS virus and development of rapid cell test for antiviral antibodies. Lancet 1985;ii:695-7.

16 Ancouturier P, Danon F, Daveau MV, et al. Measurement of serum IgG4 levels by a competitive immunoenzymatic assay with monoclonal antibodies. J Immunol Methods 1984;74: $151-62$.

17 Pincus T. Studies regarding a possible function for viruses in the pathogenesis of systemic lupus erythematosus. Arthritis Rheum 1982;25:847-56.

18 Kurata A, Katamine S, Fukuda T, et al. Production of a monoclonal antibody to a membrane antigen of human $\mathrm{T}$-cell leukaemia virus (HTLV-I/ATLV) cell lines from a systemic lupus erythematosus (SLE) patient: serological analysis for HTLV-I infection in SLE patients. Clin Exp Immunol 1985;62:65-74.

Requests for reprints to: Dr D Catovsky, MRC Leukaemia Unit, Royal Postgraduate Medical School, Du Cane Road, London W12 0HS, England. 